\title{
NDM1 producing new superbug bacteria: a threat to control infection
}

One of the biggest problems associated with the antibiotic therapy is resistance to newer drugs like carbapenems. Bacterial production of metallo-beta-lactamases (MBL) recently became ominous in the ground of infection management ${ }^{1}$. Currently, the bacteria receiving the most attention is New Delhi metallo-beta-lactamase-1 (NDM-1) producing superbug that confers resistance to most antibiotics including carbapenems. This carbapenemase is class B carbapenemase, also called metallolactamases as they require zinc at their active site. This enzyme is coded by a gene called bla - NDM -1 or gene NDM - 1. The NDM-1 enzyme was first detected in 2008 from an antibiotic-resistant bacterial infection of a Swedish national in the species of $K$. pneumoniae ${ }^{2}$. Thereby organisms bearing blaNDM-1 gene have been identified from different parts of the world and it was considered that most of the cases were arisen from Indian subcontinent ${ }^{3}$.

In Bangladesh, the situation is the same overwhelming as the global circumstances that was speculated from a study in which $22.86 \%$ NDM-1 positive isolates were detected from the imipenem resistant organisms and presence of class 1 integron in all NDM-1 producers is suggested as potential reservoir of future infection ${ }^{4}$. As previously described blaNDM-1 in mobile genetic element assume their transferability, wide dissemination of these organisms having the novel gene may cause treatment failure and expansion of devastating infection in hospital setting ${ }^{3,4}$. NDM -1 containing bacteria can be screened in laboratory by disk approximation test or Modified Hodge test and NDM -1 gene can be detected by polymerase chain reaction using specific primers. Infections caused by such bacteria are associated with high morbidity and mortality.

Treatment is guided by the antibiotic resistance pattern. Many NDM-1 strains are resistant to all antibiotics except colistin 3,4 . Colistin is an older antibiotic that has not been used much in recent decades, because it is somewhat more toxic than other antibiotics ${ }^{5}$. A few NDM-1 strains have been sensitive to tigecycline ${ }^{3,6}$. But, a recent US Food and Drug administration update warned about the increase in mortality among patients taking tigecycline as compared to other antibiotics ${ }^{7}$. A few strains have also been sensitive to aztreonam ${ }^{3}$. Researchers have identified a new antibiotic compound that may inhibit NDM-1 containing bacterial topoisomerase function so the bacterial multiplication is inhibited. Unfortunately, the compound has not yet gone through any clinical trials and is not commercially available ${ }^{8}$. Combination of two antibiotics such as imipenem and amikacin, piperacillin and amikacin synergistically inhibit NDM-1 producing bacteria determined by 4 fold decrease in MIC, piperacillin and imipenem have shown antagonism invitro when given together 9,10 . As a single agent, none of the three antibiotics (tigecycline, meropenam and colistin) showed bactericidal concentration for some carbapenemase producing strains, but tigecycline and colistin, when given together produced bactericidal effect 11 .

More and more microorganisms are developing resistance to available antibiotics because of the irrational use of antibiotics and it is a matter of concern to clinicians and health authorities. Screening for NDM-1 producing bacteria and prompt treatment of those is necessary to prevent spreading. Research should be done for the development of safe antibiotics for the treatment of these kinds of infections. Legislative changes should be made if necessary to prevent irrational use of antibiotics. At the same time clinicians should be trained about the rational use of antibiotics.

\section{References:}

1. Bebrone C. Metallo-beta-lactamases (classification, activity, genetic organization, structure, zinc coordination) and their superfamily. Biochem Pharmacol, 2007; 74 (12): 1686-701.

2. Yong D, Toleman MA, Giske CG, Cho HS, Sundman K, Lee K, Walsh TR. Characterization of a new metallobeta-lactamase gene, $b l a_{\mathrm{NDM}-1}$, and a novel erythromycin esterase gene carried on a unique genetic structure in Klebsiella pneumoniae sequence type 14 from India. Antimicrob Agents Chemother, 2009; 53 (12): 5046-54.

3. Kumarasamy KK, Toleman MA, Walsh TR, Bagaria J, Butt F, Balakrishnan R, et al. Emergence of a new antibiotic resistance mechanism in India, Pakistan and the UK: a molecular, biological and epidemiological study. Lancet Infect Dis, 2010; 10 (9): 597-602. 
4. Farzana R, Shamsuzzaman SM. Isolation \& molecular characterization of New Delhi metallo- beta-lactamase-1 producing super bug in Bangladesh. J Infect Dev Ctries, (Submitted for publication in 2011).

5. Koch-Weser J, Sidel VW, Federman EB, Kanarek P, Finer DC, Eaton AE. Adverse effects of sodium colistimethate. Manifestations and specific reaction rates during 317 courses of therapy. Ann Intern Med, 1970; 72: 857-68

6. Liang Z, Li L, Wang Y, Chen L, Kong X, Hong Y. Molecular basis of NDM-1, a new antibiotic resistance determinant. PLOS One. 2011; 6 (8): e23606. Epub 2011 Aug 24.

7. US Food and Drug Administration. FDA drug safety communications: increased risk of death with Tygacil (tigecycline) compared to other antibiotics used to treat similar infections. US Department of Health and Human Services; 2010. Available at www.fda.gov/Drugs/ DrugSafety/DrugSafetyPodcast/ucm224896.htm. [Accessed on 24 December, 2011].
8. Lewandowski N. NDM-1: Drug-resistant bacteria hits medical tourists. Web page at: expathealth.org/healthcarenews/ndm-1-hits-medical-tourists/ [accessed on Dec 9, 2012].

9. Farzana A. Imipenem registance blaNDM-1 producing Pseudomonas isolated from burn unit of Dhaka Medical College Hospital with their antimicrobial susceptibility pattern and effective combination therapy. [M.Phil thesis], Dhaka Univ., 2011.

10. Bertram MA, Young LS. Imipenem Antagonism of the In Vitro Activity of Piperacillin Against Pseudomonas aeruginosa. Antimicrob Agents Chemother, 1984,26(2): 272-274.

11. Pournaras S, Vrioni G, Neou E, Dendrinos J, Dimitroulia E, Poulou A, et al. Activity of tigecycline alone and in combination with colistin and meropenem against Klebsiella pneumoniae carbapenemase (KPC)-producing Enterobacteriaceae strains by time-kill assay. Int J Antimicrob Agents. 2011; 37(3):244-7.

Prof. Dr. S.M. Shamsuzzaman

Department of Microbiology

Dhaka Medical College 